\title{
$\mathrm{CO}$ and $\mathrm{CO}$-releasing molecules in medicinal chemistry
}

Since the discovery that $\mathrm{CO}$ acts as a cytoprotective and homeostatic molecule, increasing research efforts have been devoted to the exploitation of its therapeutic effects. Both endogenous and exogenous CO improves experimental lung, vascular and cardiac injuries and protects against several inflammatory states. The technology is now in place to bring $\mathrm{CO}$ to clinical applications, but the use of the gaseous molecule poses several problems. The challenges associated with the clinical implementation of the gas have in part been answered by the development of CO-releasing molecules (CO-RMs). As stable solid forms of $\mathrm{CO}$, these molecules represent an alternative to the administration of carbon monoxide (orally or by injection). In this article, we present insights into the biochemical action of $\mathrm{CO}$ and discuss the efficacy of $\mathrm{CO}$ and $\mathrm{CO}-\mathrm{RMs}$ in preclinical disease models. Recent advances in the $\mathrm{CO}-\mathrm{RMs}$ field are critically addressed.

co-releasing molecules (CO-RMs) are an emerging class of pharmaceutical compounds that are intended to specifically deliver $\mathrm{CO}$ to diseased or inflamed tissues in order to initiate and promote therapeutic effects at the site of disease. The potent beneficial action of CORMs is directly attributed to the biochemistry of the released CO. Healthy humans constantly produce $\mathrm{CO}$. Available data indicate production of $\mathrm{CO}$ as approximately $10 \mathrm{~cm}^{3} / \mathrm{d}$, but elevated levels are measured in patients suffering from various pathological conditions [1]. Endogenously, the formation of $\mathrm{CO}$ is due to a family of enzymes known as heme oxygenases (HOs) of which three isoforms have been identified: $\mathrm{HO}-1,-2$ and -3 [2-4]. In our body HO-1 and -2 carry out the formation of $\mathrm{CO}$ via the oxidative metabolism of heme (FIgure I), while the function of HO-3 is still unknown. HO-1, mainly found in the spleen and the liver, is the only inducible isoform of this enzymatic family. It is ubiquitously expressed in all mammalian tissues. Mounting evidence indicates that increased cellular stress will result in a cascade of stimuli ultimately leading to the up-regulation of transcription of the enzyme [2-5]. HO-2 and -3 are constitutively expressed and they are mainly found in the brain and testes. Abnormality in the function of HO's and in metabolism of their action-derived $\mathrm{CO}$ have been linked to different diseases [2].

Despite the fact these enzymes have been known for over half a century, their actionderived CO was considered for decades as only a 'byproduct' of their metabolic reactions. Today we know that the diatomic molecule plays a crucial role as a gasotransmitter, and when exogenously applied it mediates a therapeutic effect in different pathologies including cancer, neurodegenerations, hypertension, heart diseases, liver disfunctions, inflammation and infections. In medicine, $\mathrm{CO}$ applications have also advanced in the field of organ transplantation and preservation. Initially, the potential therapeutic effects of CO were demonstrated in a model of acute lung injury and subsequently, in a seminal paper by Otterbein and his group, it was demonstrated that $\mathrm{CO}$ is able to suppress the development of post-transplant arteriosclerotic lesions in rat recepients of allogenic aorta transplants [6]. Currently $\mathrm{CO}$ is evaluated in several clinical trials (Phase I-III). These include: improvement of cardiac injury after myocardial infarction (in conjunction with heme arginate, Phase I/II); anti-inflammatory effects in chronic obstructive pulmonary disease (Phase II completed); treatment of patients with intestinal paralysis after colon surgery (Phase II); prevention of lung inflammation (Phase I completed) [1]. The protective effects of $\mathrm{CO}$ as vasodilator (and probably biliverdin and bilirubin derived from the heme metabolic pathway) have also been successfully evaluated in several cardiovascular diseases including pulmonary arterial hypertension, for which there is no treatment.

Although the technology is now in place to bring $\mathrm{CO}$ to clinical applications [7], the use of the gaseous molecule poses several problems. First, the dose control of the gas is demanding. Inhaled gaseous $\mathrm{CO}$ causes direct cell

\section{Fabio Zobi}

University of Zürich,

Winterthurerstrasse 190, 8057 Zürich, Switzerland

Tel.: +4I 446354623

Fax: +4l 446356802

E-mail: fzobi@aci.uzh.ch 


\section{Key Terms}

Co-releasing molecules:

Any compound capable of

liberating $\mathrm{CO}$ under

physiological conditions. The

loss of CO may be either

spontaneous (e.g., thermal

activation) or triggered by an

external stimulus (e.g., light).

Ligands: lons or molecules that binds to a central metal atom and which, in concert with $\mathrm{CO}$, form the fundamental structure of the vast majority of CO-releasing molecules.

toxicity and rapidly reacts with hemoglobin $(\mathrm{Hb})$ owing to its much higher affinity to the protein (approximately 230 -fold) over molecular oxygen [8]. This event leads to the formation of carbonmonoxy hemoglobin ( $\mathrm{HbCO}$ ), inhibition of oxygen transport by red blood cells and subsequent tissue hypoxia. There is virtually no possibility of controlling tissue specificity in the administration of the gas. Consequently, $\mathrm{CO}$ loads tend to be high. The COVOX delivery system has now been developed by Ikaria for the administration of the gas and medical personnel will require specific training [7]. Moreover, due to safety considerations, administration of $\mathrm{CO}$ can at present only be carried out in hospital settings. The challenges associated with clinical application of the gas by inhalation have sparked the design of CO-RMs as an alternative approach to the administration of CO. Indeed,

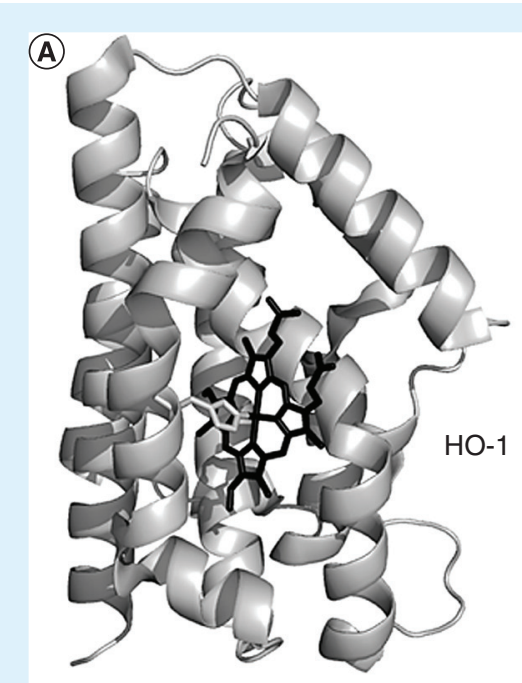

(B)

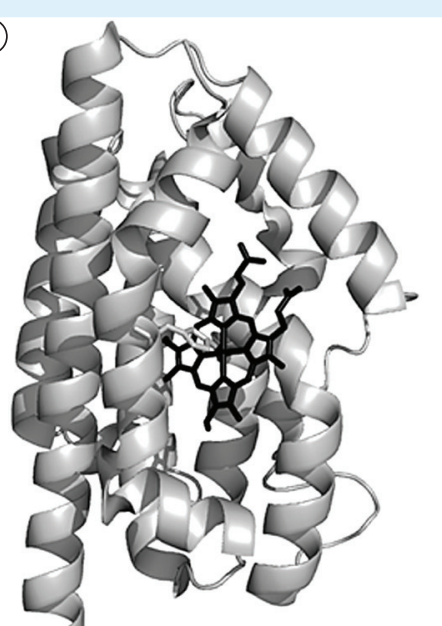

$\mathrm{HO}-2$

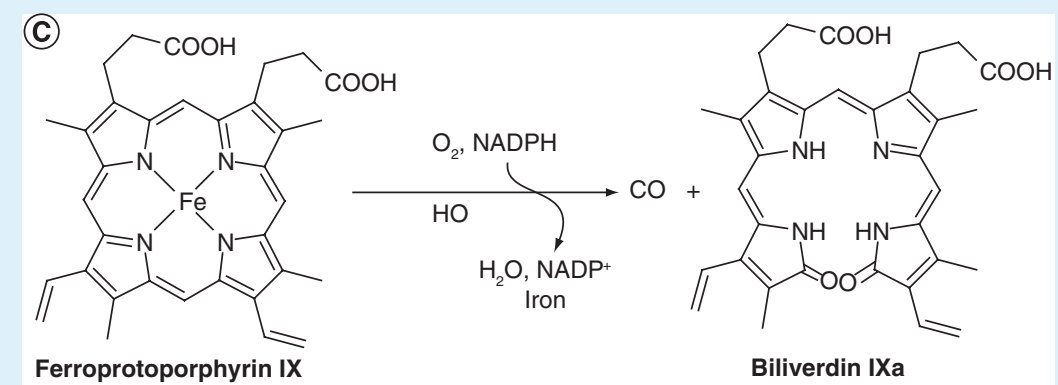

Figure 1. x-ray structures of human heme oxygenases 1 and 2 and their catalyzed heme degradation. (A) Structure of human $\mathrm{HO}-1$ (PDB access code $1 \mathrm{~N} 45)$ and (B) human HO-2 (PDB access code 2QPP) in complex with their ferroprotoporphyrin IX substrate (shown in black). (C) Endogenous regioselective $\mathrm{HO}$-catalyzed degradation of heme resulting into ferric iron, biliverdin IXa and a molecule of $\mathrm{CO}$.

HO: Heme oxygenase.
CO-releasing molecules offer the possibility, through flexible chemical design, to overcome all of the problems above. Since, ideally, CORMs can be administered orally or via injection, the right dose of administered $\mathrm{CO}$ can be conveniently calculated from the known structure of the compounds. This reduces drug (and CO) loads for the patients. Tissue specificity can be controlled by chemical variation of the drugs by, for example, appending CO-RMs to receptor targeting biomolecules. If administered orally or via injection, no equipment is needed to deliver the drug and the operation may be carried out in an ambulatory setting, thus greatly reducing overall costs.

To date, the vast majority of CO-RMs are molecules tailored around a transition metal ion (Figure 2). In general the central metal ion is not considered to play a role in the therapeutic action of CO-RMs and it may be viewed as the scaffold for the delivery of CO. However, potentially toxic elements such as chromium, whose metabolites after $\mathrm{CO}$ release, would make molecules unsuitable for further advancement to become a drug should be avoided. Factors regarding the toxicity of the central metal ion are taken in great consideration, and the field has lately seen a shift in the synthesis of CORMs modified with biocompatible elements such as iron. CO-RMs based on purely organic molecules are also known. The only examples are the boranocarbonate species introduced by Alberto [9-11]. These molecules, along with metal-based CO-RMs, have advanced to preclinical trials showing promising effects as, for example, cerebroprotective agents for the treatment of epileptic seizures [12]. In this perspective article, knowledge associated with the biochemical action of CO is evaluated and the efficacy of the diatomic molecule as a therapeutic agent is discussed. Recent advances in the CO-RMs field are critically addressed and a conceptual model for the future development of the molecules is offered. The fundamental electronic and molecular orbital theory descriptions of CO-RMs are not addressed here. The reader may refer to a recent review for an in-depth discussion of these topics [13]. In this article a strong and perhaps provocative case is argued in favor of the development of targeting CO-RMs. This opinion should not be considered exclusive and certainly other approaches are valid as well. Indeed, the reader should bear in mind that in other fields of medicinal inorganic chemistry, major metal-based drugs, for example, platinum 
and ruthenium anticancer agents, do not possess targeting ligands but are very successful pharmaceuticals.

\section{CO in biochemistry \& medicine}

The therapeutic effects of CO-RMs and of CO have been demonstrated in a large number of preclinical disease models. Motterlini and Otterbein have recently reviewed the medical applications of the molecules [7]. TABLES I \& $\mathbf{2}$ offer a brief extract of the preclinical efficacy of $\mathrm{CO}$ and selected CO-RMs on different disease models. A similar register may be found in the review article by Mann [1]. It should be mentioned that selected CO-RMs show similar effectiveness in the models listed in TABLE I and in some cases offer a superior therapeutic action over $\mathrm{CO}$ inhalation alone. For instance, the bactericidial effects of a ruthenium-based CO-RM (CO-RM-3 in Figure 2) have been shown to improve survival in immunocompetent and immunosuppressed mice, while CO gas does not seem to have a direct effect on bacteria survival [14]. The way by which CO-RMs and specifically $\mathrm{CO}$ realize their therapeutic action is largely unknown. Indeed the biochemistry of $\mathrm{CO}$ is probably best understood by its toxicity [8]. Inhaled CO will cause $\mathrm{HbCO}$ levels to rapidly increase in the blood with consequent impairment of oxygen carrying ability and hypoxia. This event is mistakenly held responsible for the toxicity of the gas, a conviction deeply rooted in the general public and the scientific community at large. In agreement with this model, serum $\mathrm{HbCO}$ levels are used diagnostically in hospitals to establish the severity of $\mathrm{CO}$ intoxication. However, the toxicity of $\mathrm{CO}$ is not a simple function of serum $\mathrm{HbCO}$ levels and such a relationship may be applied only in cases where $\mathrm{CO}$ is delivered to patients in its gaseous form [13].

The issue of whether $\mathrm{HbCO}$ is a reliable marker of $\mathrm{CO}$ poisoning is of particular importance for the medical applications of CO-RMs. The answer to the problem above has actually been available in the literature for over 30 years but it was only recently brought back into sight by Foresti and Motterlini [15]. In a recent contribution, these authors have published an old comment written by Poulton in response to the work of Aronow who affirmed that blood with elevated $\mathrm{HbCO}$ levels should not be given to patients suffering from cardiac or pulmonary dysfunctions. Via this commentary, the 1975 work of Goldbaum on the mechanism of $\mathrm{CO}$ toxicity was discussed. By using groups of dogs

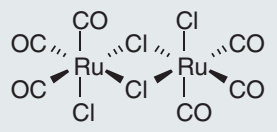

CO-RM-2

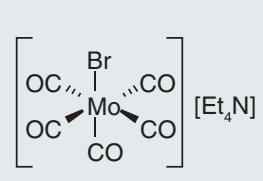

ALF062

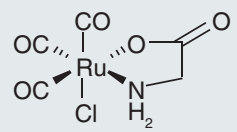

CO-RM-3

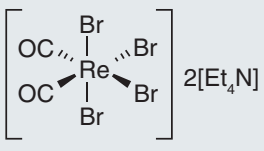

ReCO-RM-1

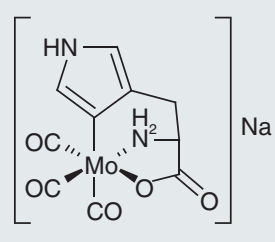

ALF186

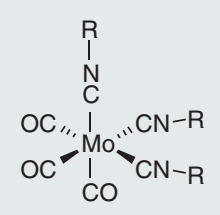

ALF795
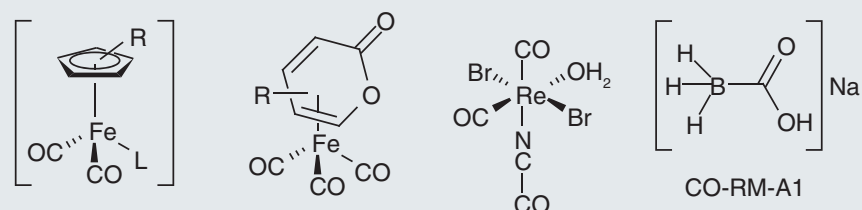

Fe-based type CO-RMs

$\mathrm{B}_{12}$-ReCO-RM-2
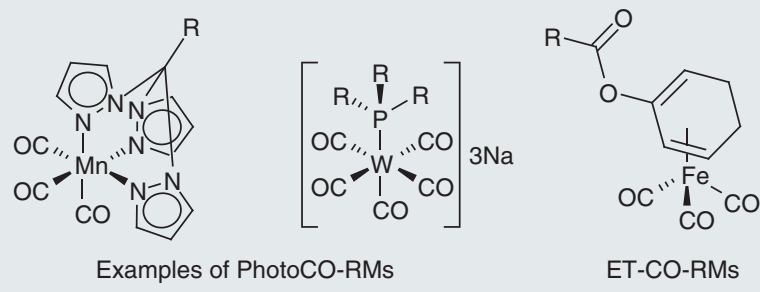

Figure 2. Structures of selected well-known CO-releasing molecules. In these examples ' $R$ ' indicates an organic substituent and ' $L$ ' a monodentate ligand. For details and references see TABLE $\mathbf{2}$.

CO-RM: CO-releasing molecule.

that were either allowed to breathe $\mathrm{CO}$ or that were bled to a severe state of anemia and then transfused with red blood cells saturated with $80 \% \mathrm{HbCO}$, Goldbaum showed that it is not the CO bound to hemoglobin that is toxic [16]. $\mathrm{Hb}$ operates in a detoxifying mechanism and it is rather the fraction of $\mathrm{CO}$ that escapes it that becomes detrimental.

Relevant to the medicinal application of CORMs, the question of what is responsible for the toxicity of $\mathrm{CO}$ remains unanswered. But, more significantly, the therapeutic sites of action of $\mathrm{CO}$ are still unknown. At present, reports on the biological targets and the sites of action of $\mathrm{CO}$ are very limited. Cytochromes and other intracellular hemoproteins are often indicated as the most likely candidates $[1-3,5,7,15,17]$. Direct evidence of the interaction of $\mathrm{CO}$ with cytochromes is available [18] but several other proteins containing various transition metals, such as manganese, copper, cobalt, nickel, vanadium or molybdenum, may potentially be targeted by $\mathrm{CO}$ [19]. Little is known about the functional significance of such

\section{Key Term}

Hemoproteins: Believed to be the major intracellular targets of $\mathrm{CO}$, they are conjugated proteins containing a metal-porphyrin compound as the prosthetic group. 


\section{Key Term}

Oxidative conditioning:

The ability of nondetrimental doses of carbon monoxideinduced reactive oxygen species generation to make cells more resistant to a subsequent insult, thus resulting in adaptation.

\section{Table 1. Effects of inhaled CO in preclinical disease models.}

\section{Disease model \\ Effect of CO gas}

Acute inflammation and lung injury in mice

Acute liver failure in mice

Prevents hyperoxia-induced lung inflammation and injury

Aortic allograft rejection in mice and rats

Prevents liver failure and injury

Asthma and airway hyperresponsiveness in

Prevents transplant vascular stenosis mice

Autoimmune disease in mice

Reverses paralysis

Bacterial infection in mice

Cardiac graft rejection in mice and rats

Cardiopulmonary bypass in pigs

Cerebral malaria in mice

Chronic colitis in mice

Hemorrhagic shock in mice

Islet cell transplantation

Kidney and liver preservation in rats

Lung allograft rejection and ischemia-

reperfusion injury in mice and rats

Myocardial infarction in mice

Postoperative ileus in mice, rats and pigs

Pulmonary and renal fibrosis in mice

Pulmonary hypertension in rats and mice

Sepsis and endotoxemia in mice, rats and pigs

Sickle cell disease in mice

Small bowel transplant

Data taken from [7] and references therein.

interactions. The physical targets responsible for mediating the protective effects of $\mathrm{CO}$ appear to be diverse. Often the effects of $\mathrm{CO}$ are found to parallel those of $\mathrm{NO}$ and in some cases $\mathrm{CO}$ action is dependent on nitric oxide production. Guanylyl cyclase is one of the rare enzymes for which direct evidence of $\mathrm{CO}$ modulation is available [20]. The polypeptide is activated by both $\mathrm{CO}$ and NO to convert guanylyl triphosphate to cGMP that then acts as an important signaling molecule. Other reports have shown that $\mathrm{CO}$ promotes its effects on mitogen-activated protein kinases, proliferator-activated receptors, signal transducers and activators of transcription, and hypoxia-inducible factors [21,22]. Recently, $\mathrm{Na}^{+}$and calcium dependent potassium channels $\left(\mathrm{K}_{\mathrm{C}^{+}}{ }^{+}\right)$have been identified as potential targets of $\mathrm{CO}$, owing to the $\mathrm{HO}-2$ function as an oxygen sensor in these systems $[23,24]$. It is interesting to note here that Guanylyl cyclase is also involved in the signaling cascade that is activated by low $\mathrm{Ca}^{2+}$ levels and inhibited by high intracellular $\mathrm{Ca}^{2+}$ concentration [25].

It is now established that among the earliest cellular responses to low concentration of exogenously applied $\mathrm{CO}$ is an increase in reactive oxygen species (ROS) formation. This event, called 'oxidative conditioning' [5], is particularly pertinent to the application of CO-RMs in the treatment of cardiac dysfunctions. There are several studies that support the idea that small amounts of applied gaseous CO will first affect cellular respiration resulting in local high concentration of ROS [26-29]. The downstream targets of ROS are unclear, but in response to ROS formation, cells reply with enhanced induction of antioxidant enzymes. The up-regulation of 'conditioning enzymes' eventually results in cellular adaptation. CO is then ascribed a (pre)conditioning role by stimulating mitochondrial ROS production and activating mitochondrial biogenesis [30-32] . Recent evidence also indicates that CO-RM-3 derived $\mathrm{CO}$ is capable of modulating activity of the most abundant and potent antioxidant enzymes, SOD1 and SOD2, found in all cells and tissues [27]. This mechanism, however, may not always be relevant when different CO-RMs are used for treatment instead of the gas. The promising class of rhenium-based CO-RMs 
Table 2. Chemical properties and major biological effects of selected CO-releasing molecules.

\begin{tabular}{|c|c|}
\hline CO-RM & Chemical properties \\
\hline ALF062 & $\begin{array}{l}\text { Soluble in DMSO; unstable under } \\
\text { aerobic conditions; } t 1 \frac{2}{2} \text { of CO release } \\
<30 \text { min }\end{array}$ \\
\hline ALF186 & $\begin{array}{l}\text { Water soluble; unstable under aerobic } \\
\text { conditions; } t 1212 \text { of } C O \text { release }<30 \mathrm{~min}\end{array}$ \\
\hline ALF492 & $\begin{array}{l}\text { Water soluble; delivers approximately } \\
1 \text { equivalent of } \mathrm{CO} \text { to } \mathrm{Mb} \text { after } 15 \mathrm{~min}\end{array}$ \\
\hline ALF795 & $\begin{array}{l}\text { Water soluble; stable under aerobic } \\
\text { conditions; complete release of all CO } \\
\text { ligands occurs within } 30-45 \mathrm{~min}\end{array}$ \\
\hline
\end{tabular}

CO-RM-1 $\left[\mathrm{Mn}_{2}(\mathrm{CO})_{10}\right]$ Soluble in DMSO; stable under aerobic conditions; photo-induced CO release

CO-RM-2

CO-RM-3

CO-RM-A1

CO-RM-F3/F6/F7/F8

$\left[\left(\eta^{4-2}\right.\right.$-pyrone)

$\mathrm{Fe}(\mathrm{CO})_{3}$ ] complexes

CO-RM-F10

$\left[\mathrm{CpMo}(\mathrm{CO})_{3} \text { (pyrone) }\right]^{+}$ (pyrone $=3$-bromo-4methoxy-6-methyl-2-

pyrone)

[(acyloxybutadiene)

$\left.\mathrm{Fe}(\mathrm{CO})_{3}\right]$ complexes

(Enzymatically-

triggered-CORMs)

$\left[\mathrm{Mn}(\mathrm{CO})_{5} \mathrm{X}\right]$ (where

$\mathrm{X}=\mathrm{Cl}, \mathrm{Br}, \mathrm{I})$

$\left[\mathrm{Mn}(\mathrm{CO})_{4}\left\{\eta^{2}-\right.\right.$

$\left.\left.\mathrm{S}_{2} \mathrm{P}(\mathrm{OEt})_{2}\right\}\right]$

$\left[\mathrm{Mn}(\mathrm{CO})_{3}(\mathrm{tmp})\right] \mathrm{PF}_{6}$

(tmp $=$ tris (pyrazoly)

methane)

ReCO-RM-1

$\mathrm{B}_{12}-\mathrm{ReCO}-\mathrm{RM}-2$
Water soluble; stable under aerobic conditions; rapid CO release in acidic conditions

Soluble in DMSO; stable under aerobic conditions; depending on $\eta^{4-2}$-pyrone substituents, release at approximately 1 equivalent of $\mathrm{CO}$ within $1 \mathrm{~h}$

Soluble in organic solvents; stable under aerobic conditions; releases 1

equivalent of $\mathrm{CO}$ within $1 \mathrm{~h}$

Soluble in DMSO; stable under aerobic conditions; depending on

acyloxybutadiene substituents, release of 0.5 equivalents of $\mathrm{CO}$ varies from $5 \mathrm{~min}$ to $8 \mathrm{~h}$.

Soluble in organic solvents; stable under aerobic conditions; $t \frac{1}{2}$ values of $\mathrm{CO}$ release ranging from approximately 2 to $24 \mathrm{~h}$

Water soluble; stable under aerobic conditions; $\mathrm{t} 1 \mathrm{2} / 2$ of $\mathrm{CO}$ release at approximately 6 min

Soluble in DMSO; stable under aerobic conditions; photo-induced CO release

Water soluble; stable under aerobic conditions; $t \frac{1}{2}$ of $\mathrm{CO}$ release at approximately 6 min

Water soluble; stable under aerobic conditions; $\mathrm{t}^{1} \frac{2}{2}$ of $\mathrm{CO}$ release at approximately $30 \mathrm{~min}$

\section{Major biological effects}

Ref.

Effective in treatment of rheumatoid arthritis (adjuvant-induced arthritis rat model) and protects against lipopolysaccharide lethality in mice

Prevents nonsteroidal anti-inflammatory drug-induced gastric ulcer

In combination with artesunate, fully protects mice from severe malaria

Effective in treatment of acetaminophen-induced acute liver failure in mice

Dilates isolated pressurized cerebral arterioles of newborn pigs and piglet pial arterioles; attenuates inflammatory response in lungs of thermally injured mice

Induces vasorelaxation; attenuates inflammatory response in lungs and liver of injured mice; activates calcium dependent potassium channels $\left(\mathrm{K}_{\mathrm{Ca}}{ }^{+}\right)$; protects against ischemia/reperfusion injuries; is a possible therapeutic drug for pulmonary hypertension

Prevents cardiac graft rejection in mice and rats; in preservation solutions improves liver and kidney function after transplant; has anti-inflammatory effects; induces vasorelaxation; prevents sepsis; effective against bacterial infection in mice; effective in treatment of rheumatoid arthritis; improves renal function; well tolerated in pigs and cynomolgus monkeys

Induces vasorelaxation; increases renal blood flow and decreases vascular resistance in mice kidneys; shows promising effects as a cerebroprotective agent for the treatment epileptic seizures

Cause vasodilatation of precontracted aortic rings; inhibition of nitrite production in murine RAW264.7 macrophages

Vasodilatation; inhibits nitrite production in murine RAW264.7 macrophages

Anti-inflammatory effects based on inhibition of inducible NO synthase

Bactericide activity, strongly reducing viability of Escherichia coli and Staphylococcus aureus

No toxicity at $100 \mu \mathrm{M}$; inhibits nitrite production in murine RAW264.7 macrophages

Photo-induced cytotoxicity against HT29 colon cancer cells comparable to the established agent 5-fluorouracil

Has antioxidative properties; protects neonatal rat cardiomyocyte against ischemia/reperfusion injury

Has antioxidative properties; protects neonatal rat cardiomyocyte against ischemia/reperfusion injury and prevents cell mortality by up to $80 \%$ 


\section{Key Term}

Photo-CO-releasing molecule: Any compound capable of liberating $\mathrm{CO}$ upon exposure to light.
(ReCORM-1 and $\mathrm{B}_{12}$-ReCORM-2 in Figure 2) [33-36], for example, is able to prevent cardiomyocyte death in an ischemia-reperfusion stress model, but mitochondrial respiration is found unaffected by treatment [34]. This observation underlines the distinct possibility that different mechanisms of protection are at play in CO-RMs-based treatments when compared with gaseous $\mathrm{CO}$ [37]. In this specific example, the ability of the rhenium compounds to act as antioxidants might explain the lack of ROS production.

\section{State of the art CO-RMs}

The discovery, identification and design of novel CO-RMs belongs to the general discipline dubbed 'medicinal inorganic chemistry'. The field is strongly interdisciplinary, encompassing traditional inorganic, organic and (bio) physical chemistry together with biology and medicine. The synthesis of CO-RMs, however, is currently a prerogative of inorganic chemists who are inevitably biased by their training. Consequently, at least in the early developments of the field, the literature has witnessed an explosion of molecules which, in the words of Whitty, "would be considered by a pharmaceutical company researcher to have little or no value" and "whose main claim to fame is that they show activity in a biochemical or cellular assay" [38]. The scientific value of the early synthetic studies should not be underestimated.

The vast majority of CO-RMs identified to date are molecules comprising elements of the metal transition series. Examples of selected metal-based CO-RMs that have been tested in vitro and/or in preclinical animal disease models are shown in Figure 2 and listed in TABLE 2 [1,7,12,14,31,34,36,39-57,101,102]. The examples provided are far from comprehensive. There are hundreds of papers describing the chemistry, the biological effects or the medical applications of CO-releasing molecules. Technically, it is not trivial to realize a metal carbonyl complex that meets all properties required for a CO-releasing agent intended as a medical drug. Beyond properties of absorption, distribution, metabolism, excretion or toxicity, inorganic medicinal chemists are faced with problems that include:

- Water solubility;

- Biocompatibility;

- Aerobic stability or stability in aqueous aerobic media;
- Rapid decay of the $\mathrm{M}(\mathrm{CO}) \mathrm{x}$ fragment in the blood;

- Fast reactions of the metal scaffold after CO release;

- Analysis of the resulting metabolites.

To further complicate matters, inorganic chemists cannot rely on organic molecules as conceptual templates for their CO-RM design. Apart from boranocarbonate species [9-11], compounds of main group elements capable of releasing $\mathrm{CO}$ are rare. Some aldehydes have been used to release $\mathrm{CO}$ and to treat arthritis [1], but other typical examples include formic acid in concentrated sulphuric acid, dichloromethane, dimethyl formamide or other similar compounds that are beyond any possible medical applicability. Also, considering also the general mistrust surrounding the use of transition metal-based drugs in medicine, chemists involved in this field are challenged with a seemingly daunting task.

Nevertheless, several CO-RMs have been tested in preclinical disease models with remarkable success. Figure 3 shows the general structure of a metal-based CO-RM. For our discussion the structure of CO-RM-3 (Figure 2) is taken as an example. The compound, of formula $\left[\mathrm{Ru}(\mathrm{CO})_{3} \mathrm{Cl}\right.$ (glycinate)], is undoubtedly the best known and most widely investigated CO-RM to date. Approximately 150 research articles have been published on this species. A single ruthenium atom (oxidation state $2+, \mathrm{d}^{6}$ low spin system) is at the core of the molecule. Three CO ligands are arranged facially around the metal ion. A deprotonated glycine, which occupies two of the remaining coordination sites, and a single chloride ion complete the coordination sphere of the molecule. Virtually almost all known CO-RMs show this type of octahedral geometry. Variations are given by the nature and the electronic structure of the central metal ion, the number and the spatial arrangement of the $\mathrm{CO}$ groups, and the type, number and coordination mode of the ancillary ligands [58,59]. Beyond structural considerations, for the purpose of this article, state-of-the-art metal-based CO-RMs will be broadly divided in two classes. The first class of molecules comprises CO-RMs in which CO release is either spontaneous or initiated by hydrolysis or redox reactions at the metal core $[33-36,42,54,60-66]$. The second class encompasses molecules for which external stimuli (e.g., light) are required in order to promote $\mathrm{CO}$ dissociation $[55,56,57,67-76]$. 


\section{Mechanisms of $\mathrm{CO}$ release}

In the simplest conceptual case, CO-RM reactions leading to $\mathrm{CO}$ loss may be ascribed to $\mathrm{CO}$ dissociation from the metal ion. Both theoretical and experimental studies have shown that $\mathrm{CO}$ dissociation is a facile step in several $\mathrm{Mn}$ - and Fe-based CO-RMs bearing dithiocarbamate ligands. In buffer solutions, an equilibrium involving release and re-coordination of $\mathrm{CO}$ is rapidly established in this family of compounds [64,77-79]. A second possible mechanism of $\mathrm{CO}$ release is generally referred to as a hydrolytic or thermal process. In this class of molecules, aquation or ligand substitution at the metal centre triggers $\mathrm{CO}$ release. The steps leading to $\mathrm{CO}$ loss are not entirely understood, but it is reasonable to assume that $\mathrm{CO}$ is liberated via an acid/ base-catalyzed, an associative, or a dissociative substitution mechanism. The latter may also be $\mathrm{pH}$ dependent. Possible mechanisms leading to CO loss are outlined in Figure 3. Often, however, the detailed description of $\mathrm{CO}$ release is more complicated than the simple scheme portrayed in Figure 3. Redox processes at the metal centre also play a role in the liberation of CO. The recently described Fe complexes with polypyridyl ligands might exemplify this issue [75]. For these compounds it has been reported that the CO-releasing behavior is critically dependent on the presence of dioxygen. The molecules are thus stable under anaerobic conditions and their CO loss has been attributed to the formation of a highly stable $\mu$-oxo diiron species (i.e., a molecule with a Fe-O-Fe bond).

The hydrolytic and redox processes are not mutually exclusive. A class of CO-RMs based on electronically unsaturated Re complexes (ReCO-RM-1 and $\mathrm{B}_{12}$-ReCO-RM-2 in Figure 2), appears to release $\mathrm{CO}$ via a combined path of mechanisms (Figure 4) [34]. When dissolved in aqueous media, three bromides in ReCORM-1 are rapidly exchanged for solvent molecules. The substitution of three $\mathrm{Br}$ by three water molecules is postulated to increase the $\operatorname{Re}^{\mathrm{I}} \rightarrow \mathrm{Re}^{\mathrm{II}}$ redox couple of Ia (FIGUre 4) to a value sufficient to drive the oxidation of $\mathrm{Br}$ to $\mathrm{BrO}^{-}$. Following reduction of the solvated $\mathrm{Re}^{\mathrm{II}}$ complex the corresponding $\mathrm{Re}^{\mathrm{I}}$ species is formed (Ib; FIgUre 4). This complex is then proposed as the CO-releasing entity liberating one equivalent of $\mathrm{CO}$ within 30 min under physiological conditions. In aqueous solutions under aerobic conditions, the monocarbonyl $\mathrm{Re}^{\mathrm{I}} \mathrm{com}$ plex is finally oxidized to the non-toxic $\mathrm{ReO}_{4}$ anion. Complexes of electronically unsaturated

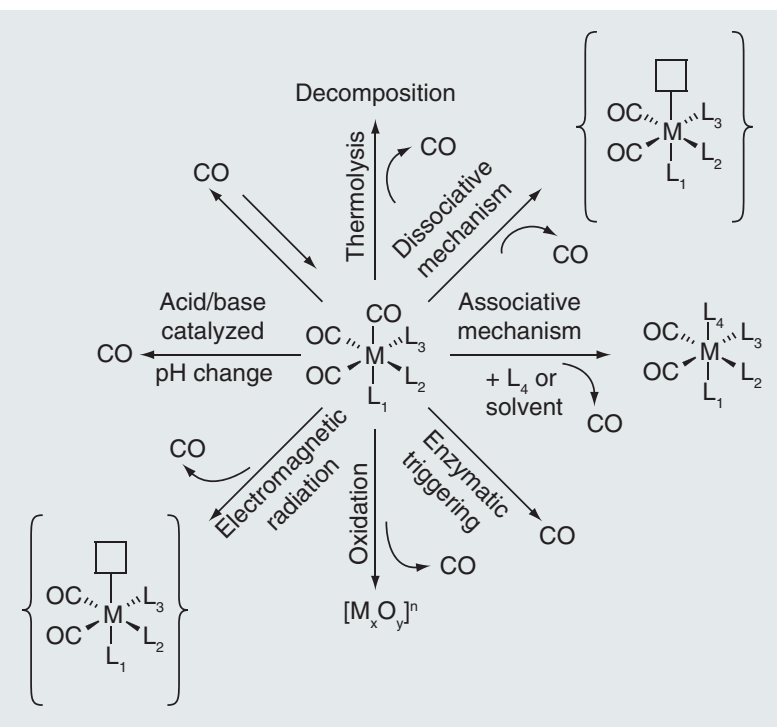

Figure 3. Possible reactions resulting in the $\mathrm{CO}$ loss from a CO-releasing molecule of general formula $\left[(C O)_{3} \mathrm{ML}_{1} \mathrm{~L}_{2} L_{3}\right]$. The loss of $\mathrm{CO}$ may be either spontaneous (e.g., thermolysis, $\mathrm{pH}$ change) or triggered by an external stimulus (e.g., electromagnetic radiation or enzymatic activation).

Re-based CO-RMs are a rare example for which both a tentative mechanism of CO loss and the final metabolite have been elucidated.

Within this first set of molecules, boranocarbonate compounds of formula $\mathrm{Na}\left[\mathrm{H}_{3} \mathrm{BCO}_{2} \mathrm{H}\right]$ (CORM-A1 in Figure 2) and $\mathrm{Na}\left[\mathrm{H}_{3} \mathrm{BCONR}_{2}\right]$ (where $\mathrm{R}$ = organic functionality) deserve to be mentioned briefly [9-11,79]. These represent the only group of nontransition-metal compounds that release CO. At physiological $\mathrm{pH}$ these molecules lose $\mathrm{CO}$ via an acid/base-catalyzed mechanism. CORM-A1 shows potential as a cerebroprotective agent for the treatment of epileptic seizures [12], it is active in the cardiovascular system [52] and reduces inflammation $[80,81]$. More than 30 papers have been published on biological applications of this compound.

The second broad class of CO-RMs are molecules for which external stimuli (e.g., light or enzymatic activation) are required in order to promote CO dissociation. Complexes comprising the $\left[\mathrm{Mn}(\mathrm{CO})_{3}\right]^{+}$core are the best-known examples of light-activated CO-RMs (Figure 2) [57,70-72,74]. These compounds, now called 'photo-CO-RMs' [69], are being developed in order to address some of the fundamental problems associated with the delivery and the tissue specificity of the drugs. Once the biodistribution of the drug is elucidated, photochemical cleavage of $\mathrm{CO}$ allows in principle to control the timing, dosage and the location of the released CO. At present, the limitation of photo-CO-RMs 


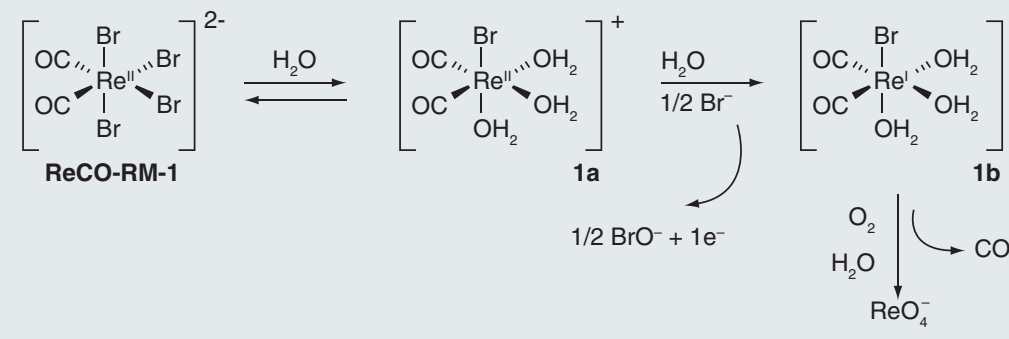

Figure 4. The proposed mechanism underlying the CO loss from an electronically unsaturated Re-based CO-releasing molecule, and its subsequent oxidation to the $\mathrm{ReO}^{4-}$ anion.

Adapted from [34].

\section{Key Terms}

Enzymatically triggered CO-releasing molecules: Molecules capable of liberating $\mathrm{CO}$ as a result of an enzymatic reaction. In general considered to be recognized as a substrate of the selected enzyme.

\section{Systemic prodrugs:}

CO-releasing molecules with no targeting functionalities, which, once administered orally or intravenously, are expected to act (i.e., release $\mathrm{CO}$ ) on the whole body. is in the radiation wavelength at which they are activated. Generally photo-CO-RMs are activated with high-frequency light in the UV range ( $h v<$ approximately $400 \mathrm{~nm}$ ) but examples are known of complexes where higher wavelengths can be used to promote $\mathrm{CO}$ loss. The $\left[\mathrm{Fe}\left(\mathrm{SCH}_{2} \mathrm{CH}_{2} \mathrm{NH}_{2}\right)_{2}(\mathrm{CO})_{2}\right]$ complex, for example, can be activated with a wavelength of $470 \mathrm{~nm}$ [82]. Thus, in general, photochemical triggering is a technique currently limited to in vivo applications to sites directly exposed to the body's surface. This represents perhaps the most pressing problem for the photo-CO-RMs community. In the words of Schatzschneider: "The main challenge in the further development of photo-CO-RMs will be to prepare compounds in which the photolytic release of $\mathrm{CO}$ can be triggered by light in the phototherapeutic window, that is at wavelengths above $600 \mathrm{~nm}$ " [71]. Three solutions have been proposed to meet the challenge above: the bathochromic shift of absorption maximum of the photo-CO-RMs via ancillary ligands with extended aromatic $\pi$-systems; the use of photo-CO-RMs with appended photosensitizers to aid in the liberation of $\mathrm{CO}$; the simultaneous absorption of two photons of identical or different frequencies to promote the $\mathrm{CO}$ releasing process via the two-photon absorption technique [71].

Enzymatically triggered CO-releasing molecules (ET-CO-RMs) are a new and interesting class of CO-RMs that have recently appeared in the literature [55,56]. The compounds, based on acyloxybutadiene tricarbonyl iron species (FIGURE 2), are activated by intracellular esterases, which, upon cleavage of the ester functionality on the acyloxybutadiene precursors, generate a highly unstable hydroxybutadiene ligand on the iron center. This reaction triggers decomposition of the molecule via oxidation of the $\left[\mathrm{Fe}(\mathrm{CO})_{3}\right]$ core ultimately leading to $\mathrm{CO}$ release. This strategy represents a new concept in the development of CO-RMs [55,56]. ET-CORMs show strong inhibition of inducible nitric oxide synthase, but their activation is currently limited to a restricted number of enzymes. Some toxicity issues still need to be addressed in this class of CO-RMs.

\section{Systemic or targeted drugs?}

CO-RMs are unlike most drugs whose pharmacological action is dependent on their interaction with a macromolecular target and whose potency is dictated by the duration of the drug-target complex persistence. In most cases, modulation of such drug-target interactions are archived by chemical variation on the periphery of the compound. Apparently small changes (as it might be the substitution of a methyl for an ethyl group) have profound consequences on the effectiveness of the drug due to conformational and structural changes around the pharmaceutical binding pocket of the macromolecule that in turn controls the dynamics of drug dissociation. CO-RMs, however, are believed to exert their therapeutic action via a completely different mechanism. Presently, they are not designed to target a specific receptor and their potential utility is generally ascribed to their fundamental ability to liberate $\mathrm{CO}$. CO-RMs are systemic prodrugs; $\mathrm{CO}$ is their 'active ingredient'. Thus, CO-RMs must survive long enough under physiological conditions and be activated only at the disease site. The half-life of the drug (e.g., in the circulatory system) is considered of great importance for the therapeutic effectiveness of the molecule. Significant research efforts continue to be dedicated to the design of CO-RMs with suitable ligands capable of modulating the half-life of CO-loss. Very recently, Atkin pointed out that "due to the diverse nature of the applications (i.e., of CO-RMs), the optimum release rate for $\mathrm{CO}$ release is not known; thus, the development of a variety of CO-RMs with different activities is desirable" [83]. This is a valid argument, but other factors will play a decisive role for the advancement of CO-RMs as acceptable pharmaceuticals.

It is now established that for any given transition metal-based CO-RM, the rate of CO release is influenced by the electronic structure of the metal and by the atoms directly bound to it. This selection of ligands forms what is defined in inorganic chemistry as the first coordination sphere of the metal ion. The development of 
clinically useful transition metal-based CORMs, however, must move beyond the simple inorganic chemistry approach. In parallel to the identification and design of, for example, octahedral, tetrahedral or square planar carbonyl complexes, the new frontier of CO-RMs research needs to address issues relevant to basic physicochemical properties required for an acceptable pharmaceutical behavior. These issues were also addressed by Romão and his team in a recent tutorial review on the development of therapeutic CO-RMs [13]. In their contribution, the authors have described a conceptual CO-RM model that takes into account both the first coordination sphere of the central metal and a second expanded sphere that they named the 'dug sphere' of the molecule. There it was argued that, within the constraints of metal carbonyl chemistry, modifications of the drug sphere should be considered to modulate druglike features of CO-RMs, and in turn address absorption, distribution, metabolism and excretion properties. Targeting functionalities could also be introduced within this second sphere.

We believe this is a valid model. Indeed, amino acids, purine and pyrimidine bases have been used since the beginning in the design of CORMs as the presence of such molecules removes toxicity issues of released ligands. We have also prepared biocompatible site-specific metal basedCO-RMs conjugated to biomolecules. Specifically, we have introduced cyanocobalamin (vitamin B12) within the drug sphere of labile $\mathrm{Re}$ (II)-based CO-RMs [34]. The idea behind the development of such bio-conjugates is to target the metallo prodrug to a specific location within the organism and thus elicit a compartmentalized homeostatic response as opposed to a systemic one that is chaotic and disordered. This goal may only be achieved by functionalizing CO-RMs with receptor targeting biomolecules in order to ensure, at least theoretically, the exclusive accumulation of the drug in the diseased organ or tissues that are intended to be treated. It is this approach that is now driving our CO-RM research program. The strategy is shown in Figure 5 - a bio-conjugated CO-RM designed for a specific target (and/or receptor) is anticipated to accumulate preferentially at the site of interest. CO-RM decomposition (i.e., $\mathrm{CO}$ release) follows the bio-carrier mediated target binding, thereby promoting $\mathrm{CO}$ passive diffusion and accumulation at the target location. It should be noted, however, that it is currently possible to administer CO-RMs locally for many of the potential
(A)

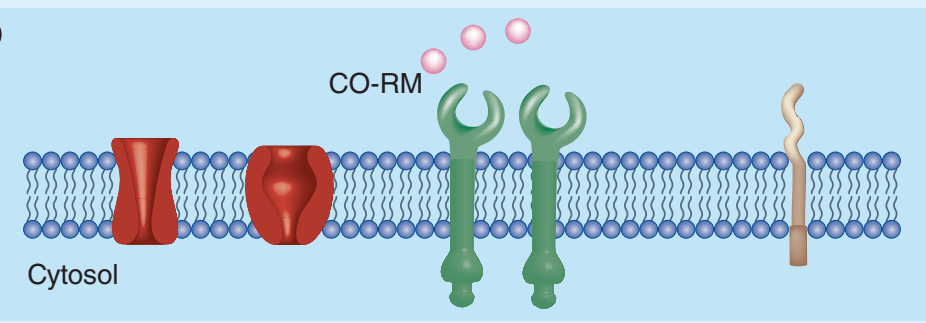

(B)

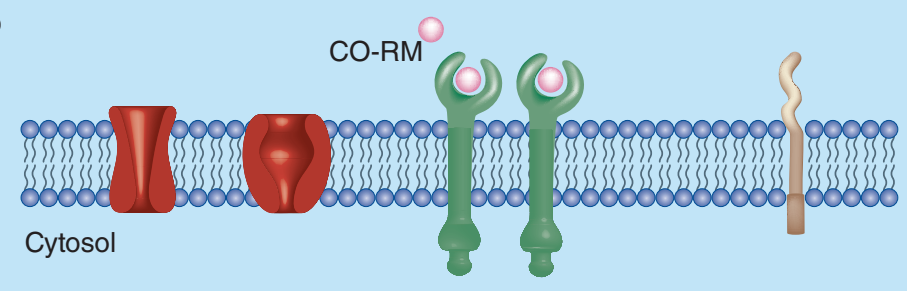

(C)

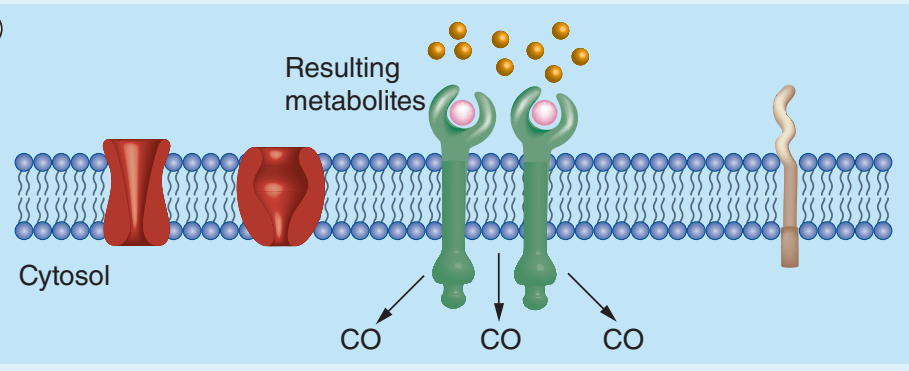

Figure 5. Development of biocompatible-site specific metal-based CO-releasing molecules. (A) Bio-conjugate CO-RM approach to target site. (B) Bio-carrier mediated receptor binding. (C) CO-RM decomposition, CO release and $\mathrm{CO}$ penetration at target site.

CO-RM: CO-releasing molecule.

applications. It is known that ALF062, CORM-3 and $\left[\left\{\mathrm{HC}\left(\mathrm{C}_{3} \mathrm{H}_{3} \mathrm{~N}_{2}\right)_{3}\right\} \mathrm{Mn}(\mathrm{CO})_{3}\right]^{+}$, for example, enter cells and as a result are likely to remain close to the site of administration $[18,39,84]$.

Nevertheless, the careful selection of targeting functionalities within the drug sphere of CORMs will not only allow a compartmentalized therapeutic effect, but will aid in overcoming the general poor water solubility of the metal complexes. Furthermore, the modulation of the drug sphere should bring CO-RMs to behave more like standard organic drugs in vivo. Thus, depending on the strength and persistence of the CORM-target (and/or receptor) complex, it would be possible to select CO-RMs with different CO-releasing profiles to promote either a rapid (i.e. with CO-RMs with short half-lives) or a continual therapeutic action. These effects could also be achieved with appended CO-RMs capable of releasing two or more equivalents of $\mathrm{CO}$ at different rates. Overall, this strategy should ultimately result in a reduced drug load for patients. 


\section{Future perspective}

The field of CO-releasing molecules is certainly gaining momentum. An increasing number of scientists are entering the CO-RM arena and in the near future we are likely to face a growing number of molecules identified for this purpose. Certainly the field will still require the invaluable input of synthetic chemists, but a shift must also occur towards more applicationoriented studies. Only a small fraction of the published compounds has advanced beyond the initial biological tests. A number of private companies (e.g., ALFAMA) are currently exploring the possible commercial value of CO-RMs. Due to patenting issues, it is likely that within the next 5 to 10 years compounds of significant medicinal value will appear in literature. Their structures will provide a new synthetic platform for the advancement of the field. At present, however, there are several problems to be solved [85]. The need to address issues relevant to basic physicochemical properties required for an acceptable pharmaceutical behavior was discussed above. In addition to that, from a chemical standpoint, more efforts should be directed towards the elucidation of

\section{Executive summary}

\section{Background}

- CO-releasing molecules (CO-RMs) and their action-derived CO mediate therapeutic effects in different pathological conditions.

- CO and CO-RMs have advanced in a wide range of medical applications. These include organ transplantation and preservation, reduction of reperfusion injury, inflammation, sepsis and killing drug-resistant bacteria.

\section{CO in biochemistry \& medicine}

- CO-RMs and CO realize their therapeutic action via largely undetermined mechanisms.

- The biological targets of CO are unknown, but cytochromes and other hemoproteins are indicated as the most likely candidates.

- $\mathrm{CO}$ is ascribed a (pre)conditioning role by stimulating mitochondrial reactive oxygen species production and activating mitochondrial biogenesis.

\section{State of the art CO-RMs}

- The vast majority of CO-RMs are molecules tailored around a transition metal ion.

- Virtually almost all known metal-based CO-RMs show an octahedral geometry.

- CO-RM design should take into account absorption, distribution, metabolism and excretion properties, toxicity, water solubility and biocompatibility.

\section{Mechanisms of $\mathrm{CO}$ release}

- CO-RMs may be broadly divided in to two types of classes: molecules in which CO release is either spontaneous or initiated by hydrolysis or redox reactions at the metal core, and molecules for which external stimuli are required in order to promote CO dissociation.

- In the simplest conceptual case, CO-RM reactions leading to CO loss may be ascribed to CO dissociation from the metal ion.

- A second possible mechanism of CO release is generally referred to as a hydrolytic or thermal process.

- CO-RMs for which external stimuli are required to promote CO dissociation are known as photo-CO-RMs (for light-activated molecules) or enzymatically-triggered CO-RMs.

- Boranocarbonate compounds are the only group of non-transition-metal CO-RMs.

\section{Systemic or targeted drugs?}

- CO-RMs are currently not designed to target specific receptors or macromolecules. They can be defined as systemic prodrugs.

- The new frontier of CO-RMs research needs to consider issues relevant to basic physicochemical properties required for an acceptable pharmaceutical behavior.

- A possible solution to address absorption, distribution, metabolism and excretion properties is via the formation of CO-RM-bioconjugate systems capable of targeting a specific location within the organism and thus elicit a compartmentalized homeostatic response as opposed to a systemic one that is chaotic and disordered.

\section{Future perspective}

- In the near future the field will likely see a shift towards more application-oriented studies.

- Due to the involvement of private companies exploring the commercial value of CO-RMs, is it is likely that within the next 5 to 10 years, compounds of significant medicinal value will appear in literature.

- The main focus of medicinal chemists should also be directed towards the generation of CO-RMs that are tissue specific, so as allow a controlled delivery of $\mathrm{CO}$.

- Targeted delivery is, however, one of the other valid approaches.

- Initiatives to foster more intensive collaborations among research groups are being promoted. 
the mechanistic details underlying CO release. Several authors have already made important contributions and, in this respect, the work of Fairlamb, Lynam and Mann is exemplary. The identification of metabolites resulting after $\mathrm{CO}$ release or decomposition of CO-RMs also requires more rigorous scientific investigation. Unlike the simple gas, $\mathrm{CO}$ is delivered by CO-RMs on a metal scaffold. The fate of the metal backbone must be elucidated from a metabolical and toxicological point of view. Existing techniques for the measurements of the $\mathrm{CO}$ release need to be perfected. Currently, $\mathrm{CO}$ detection is achieved spectroscopically either by trapping $\mathrm{CO}$ with myoglobin or hemoglobin, or with gas chromatography, $\mathrm{CO}$ electrodes or in situ infra-red techniques. It would be advantageous for the community to develop a common reliable method that could be used as the standard for all. The widely spread myoglobin assay has shortcomings. This was clearly demonstrated in recent studies [86-88]. The main focus of medicinal chemists should be directed towards the generation of CO-RMs that are tissue specific, so as to allow a controlled delivery of CO. Targeted delivery is, however, one of the other valid approaches. Thus, for example, it is acknowledged that for treatment of infections such as infected wounds, the local administration of creams containing CO-RMs is advantageous

\section{References}

Papers of special note have been highlighted as:

- of interest

-" of considerable interest

1 Mann BE. Carbon monoxide: an essential signalling molecule. Top. Organomet. Chem. 32, 247-285 (2010).

- Review of major CO-releasing molecules (CO-RMs) drawn from the chemical literature and patents with a focus on the medical and biological applications of CO-RM-2 and CO-RM-3.

2 Wu LY, Wang R. Carbon monoxide: endogenous production, physiological functions, and pharmacological applications. Pharmacol. Rev. 57(4), 585-630 (2005).

- Exhaustive review of the physiological functions of $\mathrm{CO}$.

3 Abraham NG, Kappas A. Pharmacological and clinical aspects of heme oxygenase. Pharmacol. Rev. 60(1), 79-127 (2008).

4 Ryter SW, Alam J, Choi AMK. Heme oxygenase-1/carbon monoxide: from basic over molecules designed to target CO-RMs to tissues or organs, just as the use of aerosols is superior for the treatment of lung infections. All the issues above are openly discussed in the community and concrete steps forward have already been made. Initiatives to establish a solid network among research groups are being promoted. These include the creation of a publicly accessible CO-RM library where synthetic procedures, CO-releasing profiles, the biodistribution and the therapeutic effects of different molecules are collected. Steps are being taken to foster more intensive collaborations between chemists, biologists and medical doctors in order to fully realize the potential of CO-RMs. This is probably the only possible solution to meet the ultimate challenge in the field: bringing CO-RMs into clinical use.

\section{Financial \& competing interests disclosure}

F Zobi is an employee of the Institute of Inorganic Chemistry of the University of Zürich. This work was supported by Swiss National Science Foundation (grants PZOOP2_121989 and PZOOP2_139424) and by the Institute of Inorganic Chemistry. The author has no other relevant affiliations or financial involvement with any organization or entity with a financial interest in or financial conflict with the subject matter or materials discussed in the manuscript apart from those disclosed.

No writing assistance was utilized in the production of this manuscript. science to therapeutic applications. Physiol. Rev. 86(2), 583-650 (2006).

5 Bilban M, Haschemi A, Wegiel B, Chin BY, Wagner O, Otterbein LE. Heme oxygenase and carbon monoxide initiate homeostatic signaling. J. Mol. Med. 86(3), 267-279 (2008).

6 Otterbein LE, Zuckerbraun BS, Haga M et al. Carbon monoxide suppresses arteriosclerotic lesions associated with chronic graft rejection and with balloon injury. Nat. Med. 9(2), 183-190 (2003).

7 Motterlini R, Otterbein LE. The therapeutic potential of carbon monoxide. Nat. Rev. Drug Discov. 9(9), 728-742 (2010).

- Reviews the physiology of CO, summarizes the effects of CO gas and CO-RM in preclinical animal models of cardiovascular disease, inflammatory disorders and organ transplantation, and discusses the development and therapeutic options for the exploitation of the molecules.

8 Kao LW, Nanagas KA. Toxicity associated with carbon monoxide. Clin. Lab. Med. 26(1), 99-125 (2006).
9 Pitchumony TS, Spingler B, Motterlini R, Alberto R. Derivatives of sodium boranocarbonate as novel CO-releasing molecules (CO-RMs). Chimia 62(4), 277-279 (2008).

10 Pitchumony TS, Spingler B, Motterlini R, Alberto R. Syntheses, structural characterization and $\mathrm{CO}$ releasing properties of boranocarbonate $\left[\mathrm{H}_{3} \mathrm{BCO}_{2} \mathrm{H}\right]$ - derivatives. Org. Biomol. Chem. 8(21), 4849-4854 (2010).

11 Alberto R, Motterlini R. Chemistry and biological activities of CO-releasing molecules (CORMs) and transition metal complexes. Dalton Trans. (17), 1651-1660 (2007).

12 Zimmermann A, Leffler CW, Tcheranova D, Fedinec AL, Parfenova H. Cerebroprotective effects of the CO-releasing molecule CORM-A1 against seizure-induced neonatal vascular injury. Am. J. Physiol. Heart Circ. Physiol. 293(4), H2501-H2507 (2007).

13 Romão CC, Blättler WA, Seixas JD, Bernardes GJL. Developing drug molecules for therapy with carbon monoxide. Chem. Soc. Rev. 41(9), 3571-3583 (2012). 
- Tutorial review that summarises the biological and chemical behavior of $\mathrm{CO}$, the current status of CO-RM development with a focus on the fundamental electronic and molecular orbital theory descriptions of CO-RMs.

14 Desmard M, Davidge KS, Bouvet O et al. A carbon monoxide-releasing molecule (CORM-3) exerts bactericidal activity against Pseudomonas aeruginosa and improves survival in an animal model of bacteraemia. FASEB J. 23(4), 1023-1031 (2009).

15 Foresti R, Motterlini R. Interaction of carbon monoxide with transition metals: evolutionary insights into drug target discovery. Curr. Drug Targets 11(12), 1595-1604 (2010).

16 Goldbaum LR, Ramirez RG, Absalon KB. What is the mechanism of carbon-monoxide toxicity? Aviat. Space Environ. Med. 46(10), 1289-1291 (1975).

17 Zuckerbraun BS, Chin BY, Bilban M et al. Carbon monoxide signals via inhibition of cytochrome c oxidase and generation of mitochondrial reactive oxygen species. FASEB J. 21(4), 1099-1106 (2007).

18 Davidge KS, Sanguinetti G, Yee CH et al. Carbon monoxide-releasing antibacterial molecules target respiration and global transcriptional regulators. J. Biol. Chem. 284(7), 4516-4524 (2009).

19 Boczkowski J, Poderoso JJ, Motterlini R. CO-metal interaction: vital signaling from a lethal gas. Trends in Biochem. Sci. 31(11), 614-621 (2006).

20 Ma XL, Sayed N, Beuve A, van den Akker F. $\mathrm{NO}$ and $\mathrm{CO}$ differentially activate soluble guanylyl cyclase via a heme pivot-bend mechanism. EMBO J. 26(2), 578-588 (2007).

21 Bilban M, Bach FH, Otterbein SL et al. Carbon monoxide orchestrates a protective response through PPAR gamma. Immunity 24(5), 601-610 (2006).

22 Chin BY, Jiang G, Wegiel B et al. Hypoxiainducible factor 1 alpha stabilization by carbon monoxide results in cytoprotective preconditioning. Proc. Natl Acad. Sci. USA 104(12), 5109-5114 (2007).

23 Kemp PJ. Hemeoxygenase-2 as an O-2 sensor in $\mathrm{K}^{+}$channel-dependent chemotransduction. Biochem. Biophys. Res. Commun. 338(1), 648-652 (2005).

24 Roth M, Rupp M, Hofmann S et al. Heme oxygenase-2 and large-conductance $\mathrm{Ca}\left({ }^{2+}\right)$-activated $\mathrm{K}\left({ }^{+}\right)$channels lung vascular effects of hypoxia. Am. J. Respir. Crit. Care Med. 180(4), 353-364 (2009).
25 Liu YC, Wu SN. BAY 41-2272, a potent activator of soluble guanylyl cyclase, stimulates calcium elevation and calciumactivated potassium current in pituitary GH(3) cells. Clin. Exp. Pharmacol. Physiol. 32(12), 1078-1087 (2005).

26 Tavares AFN, Teixeira M, Romao CC, Seixas JD, Nobre LS, Saraiva LM. Reactive oxygen species mediate bactericidal killing elicited by carbon monoxide-releasing molecules. J. Biol. Chem. 286(30), 26708-26717 (2011).

27 Mizuguchi S, Capretta A, Suehiro S et al. Carbon monoxide-releasing molecule CORM-3 suppresses vascular endothelial cell SOD-1/SOD-2 activity while up-regulating the cell surface levels of SOD-3 in a heparin-dependent manner. Free Radic. Biol. Med. 49(10), 1534-1541 (2010).

28 Sun BW, Zou XQ, Chen YL, Zhang P, Shi GS. Preconditioning of Carbon monoxide releasing molecule-derived $\mathrm{CO}$ attenuates LPS-induced activation of HUVEC. Int. J. Biol. Sci. 4(5), 270-278 (2008).

29 Cepinskas G, Katada K, Bihari A, Potter RF. Carbon monoxide liberated from carbon monoxide-releasing molecule CORM-2 attenuates inflammation in the liver of septic mice. Am. J. Physiol.-Gastr. Liver Physiol. 294(1), G184-G191 (2008).

30 Almeida AS, Queiroga CSF, Sousa MFQ, Alves PM, Vieira HLA. Carbon monoxide modulates apoptosis by reinforcing oxidative metabolism in astrocytes role of $\mathrm{Bcl}-2$. J. Biol. Chem. 287(14), 10761-10770 (2012).

31 Lancel S, Hassoun SM, Favory R, Decoster B, Motterlini R, Neviere R. Carbon monoxide rescues mice from lethal sepsis by supporting mitochondrial energetic metabolism and activating mitochondrial biogenesis. J. Pharmacol. Exp. Ther. 329(2), 641-648 (2009).

32 Piantadosi CA, Carraway MS, Babiker A, Suliman HB. Heme oxygenase-1 regulates cardiac mitochondrial biogenesis via Nrf2-mediated transcriptional control of nuclear respiratory factor-1. Circ. Res. 103(11), U1232-U1260 (2008).

33 Zobi F, Blacque O. Reactivity of 17 e- complex $\left[\operatorname{ReII}(\mathrm{Br})_{4}(\mathrm{CO})\left({ }_{2}\right)\right]\left({ }^{2-}\right)$ with bridging aromatic ligands. Characterization and CO-releasing properties. Dalton Trans. 40(18), 4994-5001 (2011).

34 Zobi F, Blacque O, Jacobs RA, Schaub MC, Bogdanova AY. 17 e- rhenium dicarbonyl CO-releasing molecules on a cobalamin scaffold for biological application. Dalton Trans. 41(2), 370-378 (2012).

35 Zobi F, Degonda A. CO-releasing properties of cis-trans- $\left.\left[\mathrm{Re}-\mathrm{II}(\mathrm{CO}) \mathrm{C}_{2}\right) \mathrm{Br}_{2} \mathrm{~L}_{2}\right](\mathrm{n})$ complexes. Nucl. Med. Biol. 37(6), 712-712 (2010).
36 Zobi F, Degonda A, Schaub MC, Bogdanova AY. CO releasing properties and cytoprotective effect of cis-trans- [Re-II(CO) $\left.\left.{ }_{2}\right) \mathrm{Br}_{2} \mathrm{~L}_{2}\right](\mathrm{n})$ complexes. Inorg. Chem. 49(16), 7313-7322 (2010).

37 Decaluwe K, Pauwels B, Verpoest S, Van de Voorde J. Divergent mechanisms involved in $\mathrm{CO}$ and CORM-2 induced vasorelaxation. Eur. J. Pharmacol. 674(2-3), 370-377 (2012).

38 Whitty A. Growing PAINS in academic drug discovery. Future Med. Chem. 3(7), 797-801 (2011).

39 Nobre LS, Seixas JD, Romao CC, Saraiva LM. Antimicrobial action of carbon monoxide-releasing compounds. Antimicrob. Agents Chemother. 51(12), 4303-4307 (2007).

40 Bannenberg GL, Vieira HLA. Therapeutic applications of the gaseous mediators carbon monoxide and hydrogen sulfide. Expert. Opin. Ther. Pat. 19(5), 663-682 (2009).

41 Pena AC, Penacho N, Mancio-Silva L et al. A novel carbon monoxide-releasing molecule fully protects mice from severe malaria. Antimicrob. Agents Chemother. 56(3), 1281-1290 (2012).

42 Marques AR, Kromer L, Gallo DJ et al. Generation of carbon monoxide releasing molecules (CO-RMs) as drug candidates for the treatment of acute liver injury: targeting of CO-RMs to the liver. Organometallics 31(16), 5810-5822 (2012).

43 Fiumana E, Parfenova H, Jaggar JH, Leffler CW. Carbon monoxide mediates vasodilator effects of glutamate in isolated pressurized cerebral arterioles of newborn pigs. Am. J. Physiol. Heart Circul. Physiol. 284(4), H1073-H1079 (2003).

44 Sun BW, Bihari A, Chen X et al. Carbon monoxide (CO)-releasing molecule (CORM)-liberated $\mathrm{CO}$ attenuates inflammatory response in the liver of thermally injured mice. FASEB J. 21(6), A768-A768 (2007).

45 Kooli A, Kermorvant-Duchemin E, Sennlaub $\mathrm{F}$ et al. trans-Arachidonic acids induce a heme oxygenase-dependent vasorelaxation of cerebral microvasculature. Free Rad. Biol. Med. 44(5), 815-825 (2008).

46 Sun BW, Sun H, Liu C, Shen J, Chen ZY, Chen X. Role of CO-releasing molecules liberated $\mathrm{CO}$ in attenuating leukocytes sequestration and inflammatory responses in the lung of thermally injured mice. J. Surg. Res. 139(1), 128-135 (2007).

47 Pizarro MD, Rodriguez JV, Mamprin ME et al. Protective effects of a carbon monoxidereleasing molecule (CORM-3) during hepatic cold preservation. Cryobiology 58(3), 248-255 (2009). 
48 Ferrandiz ML, Maicas N, Garcia-Amandis I et al. Treatment with a CO-releasing molecule (CORM-3) reduces joint inflammation and erosion in murine collagen-induced arthritis. Ann. Rheum. Dis. 67(9), 1211-1217 (2008).

49 Ryan MJ, Jernigan NL, Drummond HA et al. Renal vascular responses to CORM-A1 in the mouse. Pharmacol. Res. 54(1), 24-29 (2006).

50 Seveso M, Vadori M, Besenzon F et al. Anti-inflammatory responses and tolerability following the in vivo administration of a carbon monoxide-releasing molecule in primates. Xenotransplantation 12(5), 393-393 (2005).

51 Seveso M, Vadori M, Bosio E et al. Pharmacological effects and tolerability profile of a carbon monoxide-releasing molecule (CORM-3) in primates. Am. J. Transplant. 5, 306-307 (2005).

52 Kramkowski K, Leszczynska A, Mogielnicki A, Motterlini R, Chlopicki S, Buczko W. The comparison of antithrombotic properties of CORM-3 and CORM-A1 in arterial thrombosis in rats. Vasc. Pharmacol. 56(5-6), 382-382 (2012).

53 Sawle P, Hammad J, Fairlamb IJS et al. Bioactive properties of iron-containing carbon monoxide-releasing molecules. J. Pharm. Exp. Ther. 318(1), 403-410 (2006).

54 Fairlamb IJS, Lynam JM, Moulton BE et al. Eta(1)-2-pyrone metal carbonyl complexes as CO-releasing molecules (CO-RMs): a delicate balance between stability and $\mathrm{CO}$ liberation. Dalton Trans. (33), 3603-3605 (2007).

55 Romanski S, Kraus B, Guttentag M et al. Acyloxybutadiene tricarbonyl iron complexes as enzyme-triggered CO-releasing molecules (ET-CORMs): a structure-activity relationship study. Dalton Trans. 41(45), 13862-13875 (2012).

56 Romanski S, Kraus B, Schatzschneider U, Neudorf JM, Amslinger S, Schmalz HG. Acyloxybutadiene-iron tricarbonyl complexes as enzyme-triggered CO-releasing molecules (ET-CORMs). Angew. Chem. Int. Ed. 50 (18), 2392-2396 (2011).

57 Niesel J, Pinto A, N'Dongo HWP et al. Photoinduced CO release, cellular uptake and cytotoxicity of a tris(pyrazolyl) methane (tpm) manganese tricarbonyl complex. Chem. Commun. (15), 1798-1800 (2008).

58 Santos-Silva T, Mukhopadhyay A, Seixas JD, Bernardes GJL, Romao CC, Romao MJ. Towards improved therapeutic CORMs: understanding the reactivity of CORM-3 with proteins. Curr. Med. Chem. 18(22), 3361-3366 (2011).

59 Motterlini R. Carbon monoxide-releasing molecules (CO-RMs): vasodilatory, anti-ischaemic and anti-inflammatory activities. Biochem. Soc. Trans. 35, 1142-1146 (2007).

60 Hewison L, Crook SH, Johnson TR et al. Iron indenyl carbonyl compounds: $\mathrm{CO}-$ releasing molecules. Dalton Trans. 39(38), 8967-8975 (2010).

61 Zhang WQ, Whitwood AC, Fairlamb IJS, Lynam JM. Group 6 carbon monoxidereleasing metal complexes with biologicallycompatible leaving groups. Inorg. Chem. 49(19), 8941-8952 (2010).

62 Atkin AJ, Williams S, Sawle P, Motterlini R, Lynam JM, Fairlamb IJS. Mu(2)-Alkyne dicobalt $(0)$ hexacarbonyl complexes as carbon monoxide-releasing molecules (CO-RMs): probing the release mechanism. Dalton Trans. (19), 3653-3656 (2009).

63 Scapens D, Adams H, Johnson TR et al. [(eta$\left.\left.\left.\mathrm{C}_{5} \mathrm{H}_{4} \mathrm{R}\right) \mathrm{Fe}(\mathrm{CO}) \mathrm{C}_{2}\right) \mathrm{X}\right], \mathrm{X}=\mathrm{Cl}, \mathrm{Br}, \mathrm{I}$, $\mathrm{NO}_{3}, \mathrm{CO}_{2} \mathrm{Me}$ and $\left[\left(\right.\right.$ eta- $\left.\left.\mathrm{C}_{5} \mathrm{H}_{4} \mathrm{R}\right) \mathrm{Fe}(\mathrm{CO})\left(_{3}\right)\right]$ $(+), \mathrm{R}=\left(\mathrm{CH}_{2}\right)(\mathrm{n}) \mathrm{CO}_{2} \mathrm{Me}(\mathrm{n}=0-2)$, and $\mathrm{CO}_{2} \mathrm{CH}_{2} \mathrm{CH}_{2} \mathrm{OH}$ : a new group of $\mathrm{CO}-$ releasing molecules. Dalton Trans. (43), 4962-4973 (2007).

64 Crook SH, Mann BE, Meijer AJHM et al. $\left[\mathrm{Mn}(\mathrm{CO})\left({ }_{4}\right)\left\{\mathrm{S}_{2} \mathrm{CNMe}\left(\mathrm{CH}_{2} \mathrm{CO}_{2} \mathrm{H}\right)\right\}\right]$, a new water-soluble CO-releasing molecule. Dalton Trans. 40 (16), 4230-4235 (2011).

65 Johnson TR, Mann BE, Teasdale IP et al. Metal carbonyls as pharmaceuticals? $\left[\mathrm{Ru}(\mathrm{CO})\left({ }_{3}\right) \mathrm{Cl}\right.$ (glycinate) $]$, a CO-releasing molecule with an extensive aqueous solution chemistry. Dalton Trans. (15), 1500-1508 (2007).

66 Bikiel DE, Solveyra EG, Di Salvo F et al. Tetrachlorocarbonyliridates: water-soluble carbon monoxide releasing molecules rate-modulated by the sixth ligand. Inorg. Chem. 50(6), 2334-2345 (2011).

67 Rimmer RD, Pierri AE, Ford PC. Photochemically activated carbon monoxide release for biological targets. Toward developing air-stable photoCORMs labilized by visible light. Coord. Chem. Rev. 256(15-16), 1509-1519 (2012).

- Overview of recent efforts regarding photo-activated $\mathrm{CO}$ releasing moieties based on manganese, iron and group 6 metals.

68 Zhang WQ, Atkin AJ, Fairlamb IJS, Whitwood AC, Lynam JM. Synthesis and reactivity of molybdenum complexes containing functionalized alkynyl ligands: a photochemically activated CO-releasing molecule (PhotoCO-RM). Organometallics 30(17), 4643-4654 (2011).

69 Rimmer RD, Richter H, Ford PC. A photochemical precursor for carbon monoxide release in aerated aqueous media. Inorg. Chem. 49(3), 1180-1185 (2010).

70 Mohr F, Niesel J, Schatzschneider U, Lehmann CW. Synthesis, structures, and CO releasing properties of two tricarbonyl manganese(I) complexes. Z. Anorg. Allg. Chem. 638(3-4), 543-546 (2012).

71 Schatzschneider U. PhotoCORMs: Light-triggered release of carbon monoxide from the coordination sphere of transition metal complexes for biological applications. Inorg. Chim. Acta 374(1), 19-23 (2011).

72 Dordelmann G, Pfeiffer H, Birkner A, Schatzschneider U. Silicium dioxide nanoparticles as carriers for photoactivatable CO-releasing molecules (PhotoCORMs). Inorg. Chem. 50 (10), 4362-4367 (2011).

73 Schatzschneider U. Photoactivated biological activity of transition-metal complexes. Eur. J. Inorg. Chem. 2010(10), 1451-1467 (2010).

74 Kunz PC, Huber W, Rojas A, Schatzschneider $\mathrm{U}$, Spingler B. Tricarbonylmanganese(I) and -rhenium(I) complexes of imidazol-based phosphane ligands: influence of the substitution pattern on the $\mathrm{CO}$ release properties. Eur. J. Inorg. Chem. 2009(35), 5358-5366 (2009).

75 Gonzalez MA, Fry NL, Burt R, Davda R, Hobbs A, Mascharak PK. Designed iron carbonyls as carbon monoxide (CO) releasing molecules: rapid CO release and delivery to myoglobin in aqueous buffer, and vasorelaxation of mouse aorta. Inorg. Chem. 50 (7), 3127-3134 (2011).

76 Jackson CS, Schmitt S, Dou QP, Kodanko JJ. Synthesis, characterization, and reactivity of the stable iron carbonyl complex $[\mathrm{Fe}(\mathrm{CO})$ $\left.\left(\mathrm{N}_{4} \mathrm{Py}\right)\right]\left(\mathrm{ClO}_{4}\right)\left({ }_{2}\right)$ : photoactivated carbon monoxide release, growth inhibitory activity, and peptide ligation. Inorg. Chem. 50(12), 5336-5338 (2011).

77 Vummaleti SVC, Branduardi D, Masetti M, De Vivo M, Motterlini R, Cavalli A. Theoretical insights into the mechanism of carbon monoxide $(\mathrm{CO})$ release from CO-releasing molecules. Chem. Eur. J. 18(30), 9267-9275 (2012).

78 Hewison L, Crook SH, Mann BE et al. New types of CO-releasing molecules (CO-RMs), based on iron dithiocarbamate complexes and $\left[\mathrm{Fe}(\mathrm{CO})\left({ }_{3}\right) \mathrm{I}\left(\mathrm{S}_{2} \mathrm{COEt}\right)\right]$. Organometallics, 31(16), 5823-5834 (2012).

79 Motterlini R, Sawle P, Bains S et al. CORM-A1: a new pharmacologically active carbon monoxide-releasing molecule. FASEB J. 18(14), 284-268 (2004).

80 Fagone P, Mangano K, Quattrocchi C et al. Prevention of clinical and histological signs of proteolipid protein (PLP)-induced 
experimental allergic encephalomyelitis (EAE) in mice by the water-soluble carbon monoxide-releasing molecule (CORM)-A1 Clin. Exp. Immunol. 163(3), 368-374 (2011).

81 Halilovic A, Patil KA, Bellner L et al. Knockdown of heme oxygenase-2 impairs corneal epithelial cell wound healing. J. Cell. Physiol. 226(7), 1732-1740 (2011).

82 Kretschmer R, Gessner G, Gorls H, Heinemann SH, Westerhausen M.

Dicarbonyl-bis(cysteamine)iron(II) a light induced carbon monoxide releasing molecule based on iron (CORM-S1). J. Inorg. Biochem. 105(1), 6-9 (2011).

83 Atkin AJ, Fairlamb IJS, Ward JS, Lynam JM. CO Release from norbornadiene iron $(0)$ tricarbonyl complexes: importance of ligand dissociation. Organometallics 31(16),
5894-5902 (2012).

84 Meister K, Niesel J, Schatzschneider U, Metzler-Nolte N, Schmidt DA, Havenith M. Label-free imaging of metal-carbonyl complexes in live cells by raman microspectroscopy. Angew. Chem. Int. Ed. 49(19), 3310-3312 (2010).

85 Mann BE. CO-Releasing molecules: a personal view. Organometallics 31(16), 5728-5735 (2012).

86 Huber W, Linder R, Niesel J, Schatzschneider U, Spingler B, Kunz PC. A comparative study of tricarbonylmanganese photoactivatable $\mathrm{CO}$ releasing molecules (PhotoCORMs) by using the myoglobin assay and time-resolved IR spectroscopy. Eur. J. Inorg. Chem. 2012(19), 3140-3146 (2012).
87 McLean S, Mann BE, Poole RK. Sulfite species enhance carbon monoxide release from CO-releasing molecules: implications for the deoxymyoglobin assay of activity. Anal. Biochem. 427(1), 36-40 (2012).

88 Atkin AJ, Lynam JM, Moulton BE et al. Modification of the deoxy-myoglobin/ carbonmonoxy-myoglobin UV-vis assay for reliable determination of $\mathrm{CO}$-release rates from organometallic carbonyl complexes. Dalton Trans. 40(21), 5755-5761 (2011).

\section{- Patents}

101 Romao CC, Rodrigues SS, Seixas JD et al.: WO2007/35105 (2007).

102 Hemocorm Ltd, University of Sheffield: WO003953 (2008). 